\title{
RESÍDUOS SÓLIDOS NO MUNICÍPIO DE PERDIZES (MG): UMA CARTILHA EDUCATIVA
}

\author{
Raíssa Ferreira Alves ${ }^{1}$ \\ Joyce Silvestre de Sousa ${ }^{2}$
}

Resumo: A gestão de resíduos sólidos no Brasil é uma temática que vem sendo discutida há algum tempo pelo grande desequilíbrio que gera aos ecossistemas, principalmente através da poluição. Soluções estão sendo cada vez mais discutidas, entre as quais destaca-se, a Educação Ambiental. O objetivo deste trabalho é levantar a forma como os resíduos sólidos são geridos no município de Perdizes (MG), apresentando os resultados em formato de cartilha educativa. A metodologia utilizada foi baseada nos estudos de Alves, Gutjahr e Pontes (2019). Como produto, foi estruturado uma cartilha didática com informações tanto locais quanto gerais, mas de grande importância para a comunidade, a fim de se obter uma maior eficiência na coleta e gestão de resíduos sólidos.

Palavras-chave: Educação Ambiental; Segregação de Resíduos; Usina de Triagem de Resíduos; Gestão de Resíduos Sólidos.

\begin{abstract}
Solid waste management in Brazil is a topic that has been discussed for some time by the great imbalance it generates to ecosystems, mainly through pollution. Solutions are being increasingly discussed among which stands out, environmental education. The objective of this paper is to survey the way solid waste is managed in the municipality of Perdizes (MG, Brazil), presenting the results in an educational booklet format. The methodology used was based on the studies by Alves, Gutjahr and Pontes (2019). As a product, a didactic booklet was structured with local and general information, but of great importance for the community, in order to obtain greater efficiency in the collection and management of solid waste.
\end{abstract}

Keywords: Environmental Education; Waste Segregation; Waste Sorting Plant; Solid Waste Management.

\footnotetext{
${ }^{1}$ Instituto Federal de Educação, Ciência e Tecnologia do Triangulo Mineiro- Campus Uberaba. E-mail: raissaalvesbio@gmail.com

2 Instituto Federal de Educação, Ciência e Tecnologia do Triangulo Mineiro- Campus Uberaba. E-mail: joyce@iftm.edu.br
} 


\section{Introdução}

A questão ambiental é considerada uma área cada vez mais urgente e importante para a sociedade, pois o futuro da humanidade depende da sua relação com a natureza (ROHDEN, 2005).

Neste contexto, um dos maiores problemas ambientais é a produção do lixo. Os resíduos sólidos urbanos (RSU), são os principais responsáveis pela produção de material sólido em uma bacia hidrográfica urbana de ocupação consolidada. Dentre os principais efeitos dos resíduos sólidos sobre o sistema de drenagem, pode-se citar: obstrução dos canais, aumento da frequência de inundações e contaminação das águas (TUCCI, PORTO E BARROS, 1995). A rede de drenagem urbana está entre as principais responsáveis pela veiculação de cargas poluidoras, constituindo-se em um importante fator de degradação dos corpos hídricos (TUCCI, 2002).

Quando acontece o reaproveitamento da fração reciclável de resíduos produzidos, propicia a minimização da poluição ambiental e a melhoria da qualidade de vida da população (FADINI; FADINI, 2005).

Sendo assim, a participação da comunidade é imprescindível nas práticas da Gestão de Resíduos Sólidos. Faz-se necessário expor diferentes valores, percepções e hábitos, para que a comunidade compreenda de forma clara e objetiva a importância de suas atitudes nas etapas de gestão dos resíduos sólidos, buscando uma visão socioeducativa e política.

O objetivo geral do estudo é apresentar uma cartilha educativa, elaborada a partir do levantamento das ações de destinação dos resíduos sólidos do município de Perdizes (MG).

\section{Metodologia}

O município de Perdizes está situado na Região do Alto Paranaíba, localizado próximo ao Triângulo Mineiro, no estado de Minas Gerais; e possui $2.457,60 \mathrm{~km}^{2}$ de extensão territorial e uma população de mais de 16.168 habitantes. A base econômica do município é a pecuária e agricultura (IBGE, 2019).

A microbacia onde o Município de Perdizes está inserida é a Bacia Hidrográfica do Rio Araguari, que está localizada a Oeste do território do Estado de Minas Gerais, inserida, parcialmente, nas Macrorregiões do Triângulo Mineiro e Alto Paranaíba. Sua área total é de $22.091 \mathrm{~km}^{2}$ e influencia, aproximadamente, 1,2 milhão de pessoas divididas em 20 municípios (PERDIZES, 2019).

A metodologia utilizada baseia-se nos estudos de Alves, Gutjahr e Pontes (2019). O diagnóstico da gestão dos resíduos foi realizado por meio de 2 visitas in loco na usina de triagem do município de Perdizes- MG, nos meses de Julho e Agosto/2019, onde se obteve informações locais da situação dos resíduos, quantidade e coleta dos mesmos. As demais informações, como valores gastos no transporte dos resíduos sólidos, locais de disposição final dos mesmos, dentre outros, foram obtidas a partir de pesquisa bibliográfica e exploratória, no site da Prefeitura Municipal e na Secretaria de Meio Ambiente. 
A ferramenta para a diagramação da cartilha foi o Microsoft Power Point 2010, com formatação em tamanho A6, fonte Time New Roman, tamanho 24 na capa e no título de cada seção e tamanho variando entre 12 e 20 no corpo do manuscrito.

\section{Resultados e discussão}

O município de Perdizes (MG) conta com uma usina de separação e triagem dos resíduos sólidos urbanos, para onde é levado todo o material recolhido. Após os resíduos serem descarregados na boca da esteira, eles são separados em categorias, onde plásticos, papéis e papelões são prensados, e os demais materiais recicláveis são separados em sacos plásticos, denominados big bags. Os materiais recicláveis são encaminhados para uma usina de reciclagem no município de Patrocínio-MG, e os não recicláveis são transportados para um aterro sanitário privado, na cidade de Uberaba-MG. São coletados cerca de $15.000 \mathrm{~kg} / \mathrm{dia}$ de resíduos e a coleta é realizada diariamente (PERDIZES, 2019). Observou-se que os resíduos sólidos urbanos chegam na usina de separação e triagem do município bastante misturados, perdendo as características de reciclagem dos mesmos.

O material contém uma capa que apresenta o título da cartilha, uma imagem da entrada da cidade e o nome das autoras; possui uma contracapa com o símbolo do Instituto Federal do Triangulo Mineiro- Campus Uberaba e a logo da Prefeitura Municipal de Perdizes (Figura 1).

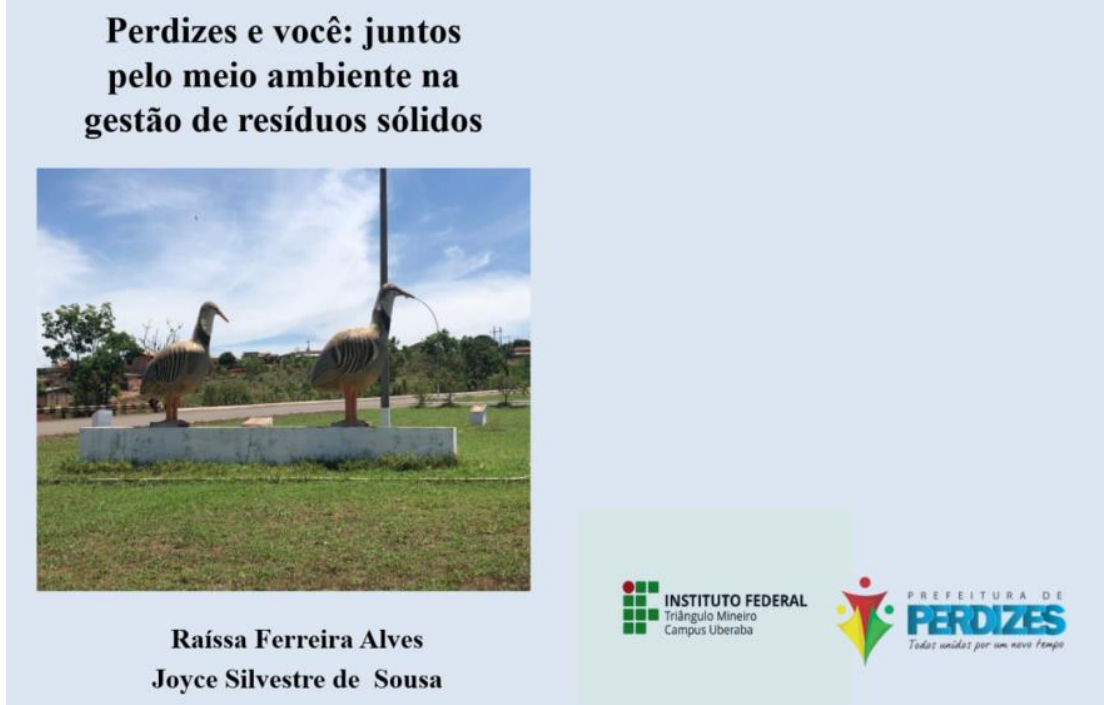

Figura 1: Capa da cartilha sobre resíduos sólidos. Fonte: Do autor (2019).

$\mathrm{Na}$ cartilha, além da capa, há também outros elementos pré-textuais, como: a apresentação que expõe brevemente o objetivo da cartilha, a necessidade de práticas de Educação Ambiental e a situação em que os resíduos sólidos chegam na usina de triagem (Figura 2). 


\section{Apresentação}

Esta cartilha é produto de um
estudo de campo realizado em
2019 na cidade de Perdizes- MG,
referente ao trabalho de conclusão
de curso pelo programa de pós-
graduação em Gestão Ambiental:
diagnóstico e adequação do
Instituto Federal do Triângulo
Mineiro (IFTM)- campus
Uberaba. a quantidade de
Foi estimada a no
residuos sólidos gerada no
municipio e realizou-se pesquisas
sobre suas formas de destinação.
A necessidade de práticas de
educação ambiental no município
se mostrou de grande importância.

Essa constatação se apresenta tendo em vista que os resíduos sólidos gerados chegam na usina de triagem misturados a ponto de perderem seu valor agregado e suas possibilidades de reciclagem.

Esta cartilha tem como objetivo mostrar a realidade do município em relação a gestão dos resíduos sólidos, além de propor possiveis alternativas de melhorias de acordo com a realidade local. O material didático foi elaborado em linguagem simples e de fácil entendimento, com esquemas e ilustrações para melhor compreensão dos aspectos estudados.

Figura 2: Texto de apresentação da cartilha escrito pelas autoras.

Fonte: Do autor (2019)

Para uma apresentação mais didática e estruturada, os elementos textuais foram organizados em tópicos, facilitando assim a leitura.

\section{(1) Conhecendo o Município:}

Neste tópico, a cartilha faz uma breve apresentação do município de Perdizes, abordando sobre sua base econômica, quantidade de habitantes, bacia hidrográfica em que o município está inserido, mapa de localização e pontos turísticos na cidade (Figura 3 e 4).

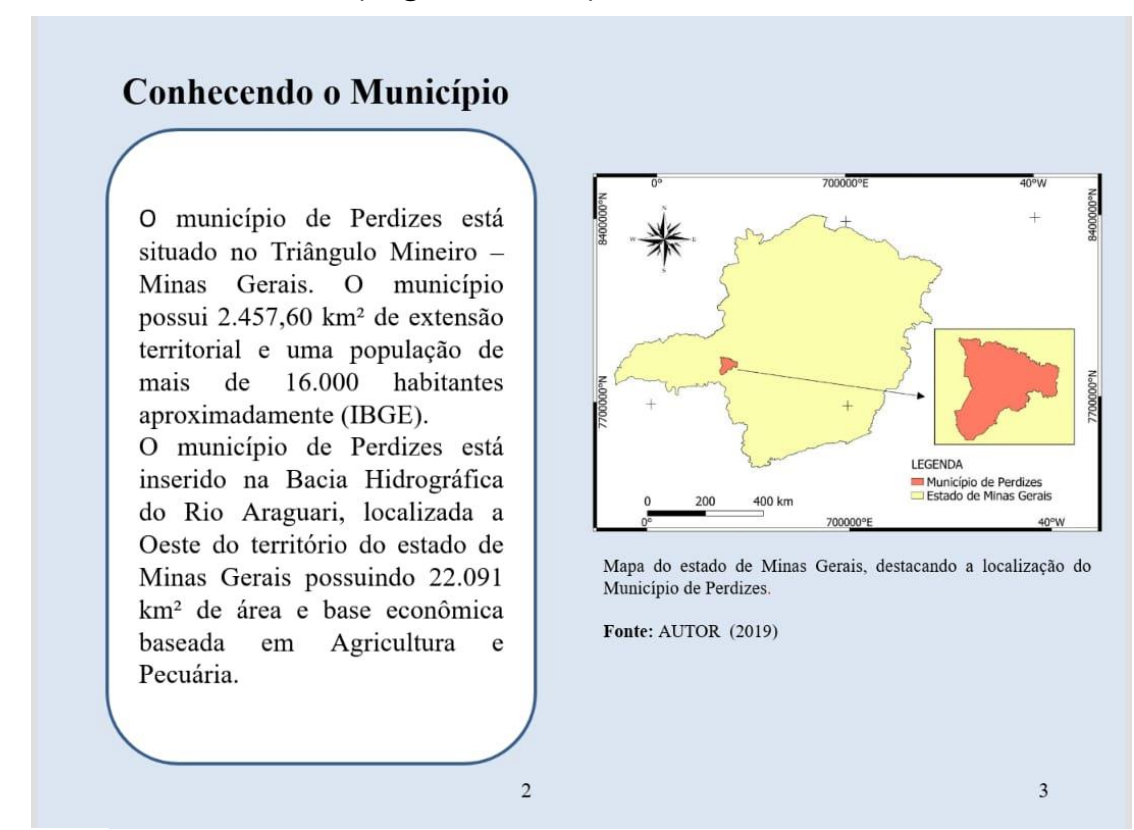

Figura 3: Tópico da cartilha educativa abordando informações sobre o município.

Fonte: Do autor (2019) 

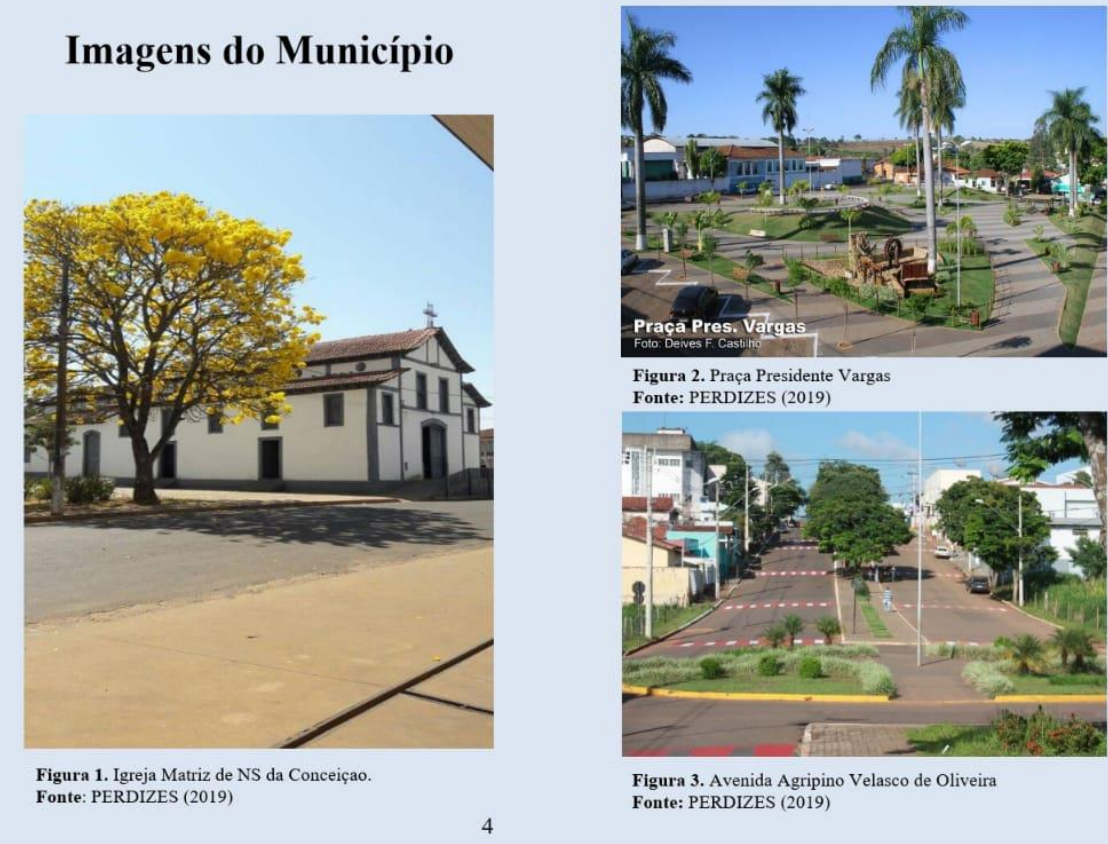

Figura 3. Avenida Agripino Velasco de Oliveira Fonte: PERDIZES (2019)

Figura 4: Tópico da cartilha educativa ilustrando pontos turísticos do município.

Fonte: Do autor (2019)

\section{(2) Coleta de resíduos no município}

Neste tópico descreve-se como é realizada a coleta de resíduos sólidos urbanos no município, a quantidade diária recolhida, a forma de coleta na zona rural e o local onde esse resíduo é transportado (Figura 5).

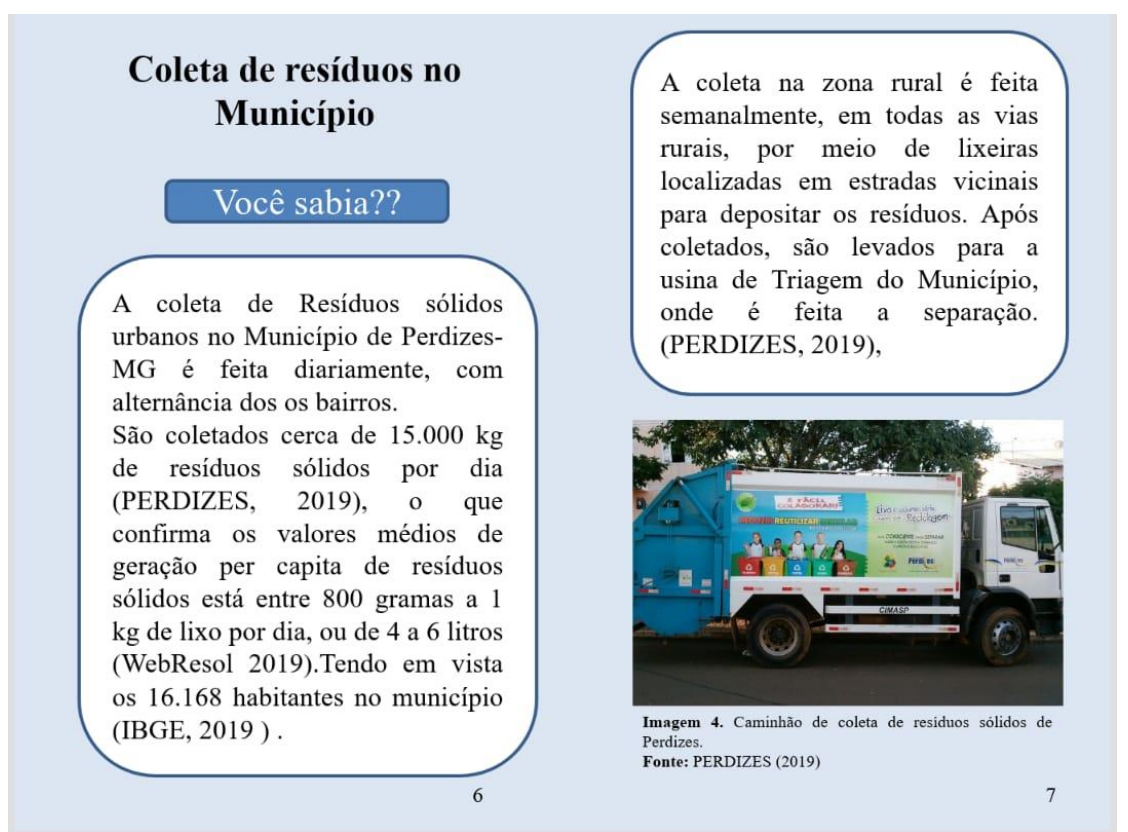

Figura 5: Coleta de resíduos do município

Fonte: Do autor (2019) 


\section{(3) Tipos de resíduos}

Nesta seção abordou-se sobre os tipos de resíduos e seu tempo de decomposição, assim como a diferença entre resíduos recicláveis, não recicláveis e orgânicos (Figuras 6,7 e 8).

\section{(4) Tipos de materiais recicláveis}

Nesta seção, destaca-se os tipos de materiais que podem ser reciclados e os que não podem ser reciclados, de acordo com cada categoria (Figura 9 e $10)$.

\section{(5) Responsabilidade dos resíduos sólidos}

Neste tópico, tratamos sobre a responsabilidade dos resíduos sólidos gerados. (Figura 10).

\section{Tipos de Resíduos}

Resíduos Sólidos é tudo aquilo que, de alguma forma, podem ser reaproveitados.

Lixo: é tudo aquilo que não tem como se aproveitar, ou seja, já foram esgotadas todas as possibilidades.

Tempo de decomposição dos resíduos é o tempo que eles demoram para se decompor e desaparecer do meio.

S.A Corumbá Concessões, 2013
Cada material tem um tempo diferente de decomposição.

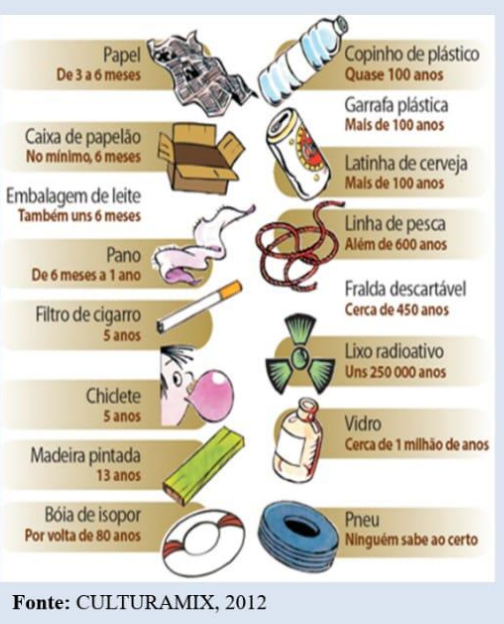

Figura 6: Tipos de resíduos e tabela de tempo de decomposição.

Fonte: Do autor (2019) 


\section{Resíduos recicláveis, Resíduos não recicláveis e Resíduos Orgânicos}

\section{Resíduos recicláveis: nova destinação.}
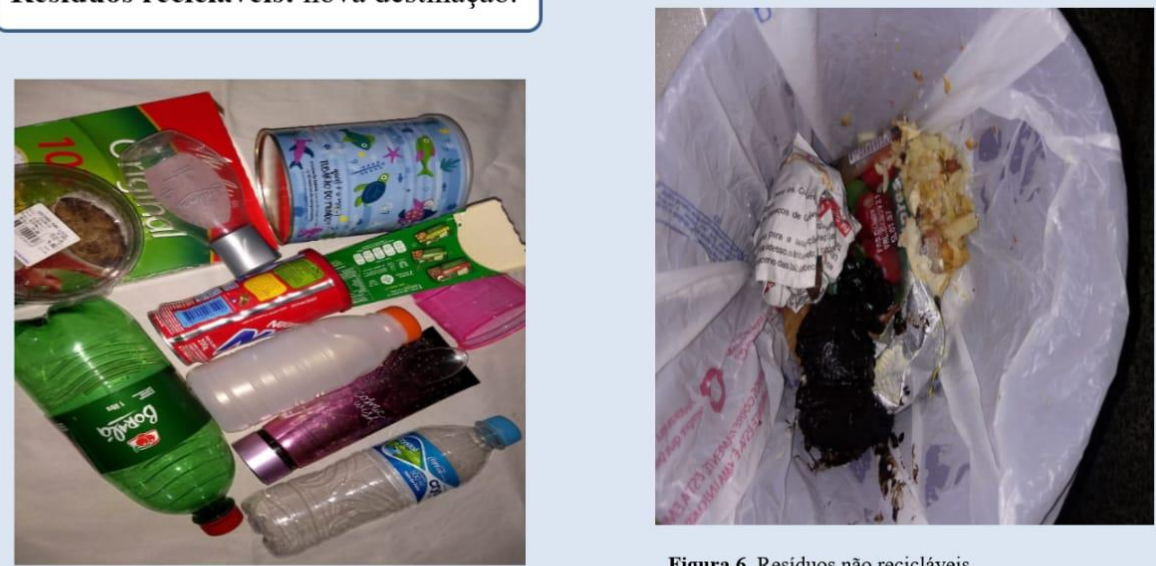

Figura 5. Resíduos recicláveis.

Figura 6. Resíduos não recicláveis. Fonte: AUTOR (2019)

Figura 7: Resíduos recicláveis e não recicláveis

Fonte: Do autor (2019)

\section{Resíduos orgânicos: de origem} vegetal, se degradam espontaneamente.

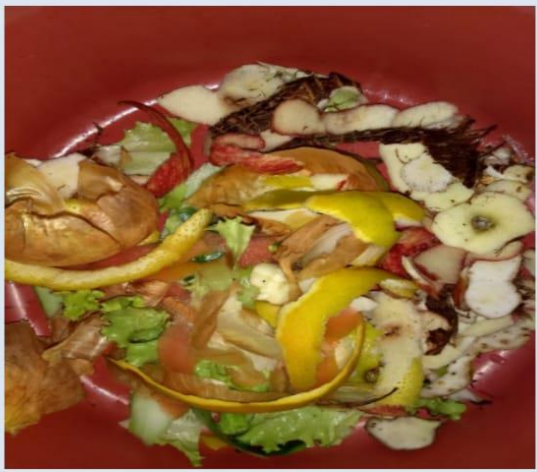

Figura 7. Resíduo doméstico. Fonte: AUTOR (2019)
Rejeitos: depois de esgotadas todas as possibilidades, deve ter a disposição final ambientalmente adequada (PNRS, 2010);

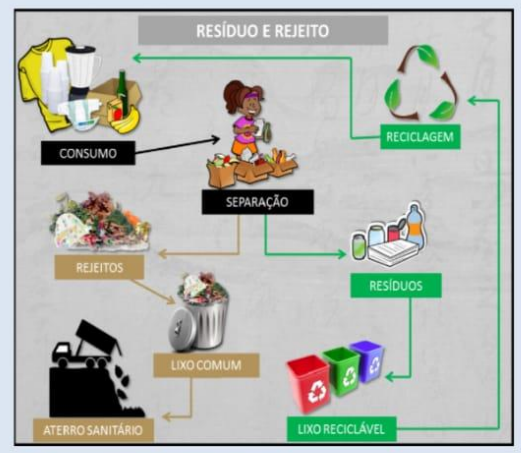

Fonte: RECICLART (2015)

12

Figura 8: Resíduos orgânicos.

Fonte: Do autor (2019) 


\section{Tipos de materiais recicláveis}

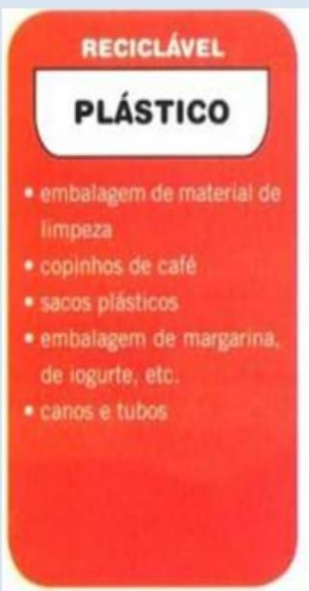

Fonte: SOESCOLA (2019).
NẢO-RECICLÁVEL

- cabo de panela

- tomadas

- embalagem

de biscoito

- misturas de papel,

plásticos e metais

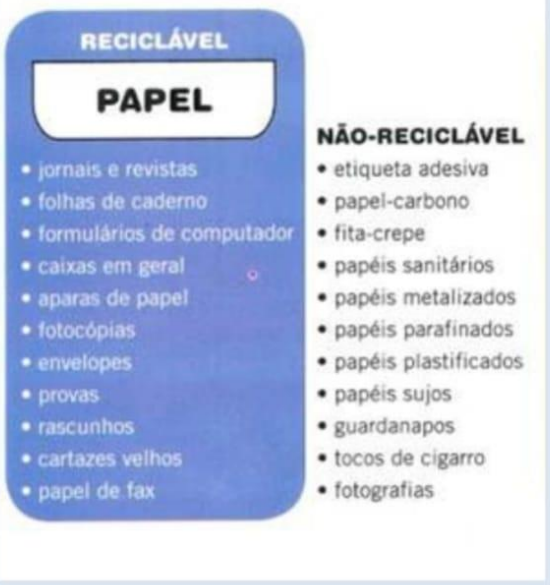

Fonte: SOESCOLA (2019).

Figura 9: Tipos de materiais recicláveis.

Fonte: Do autor (2019)

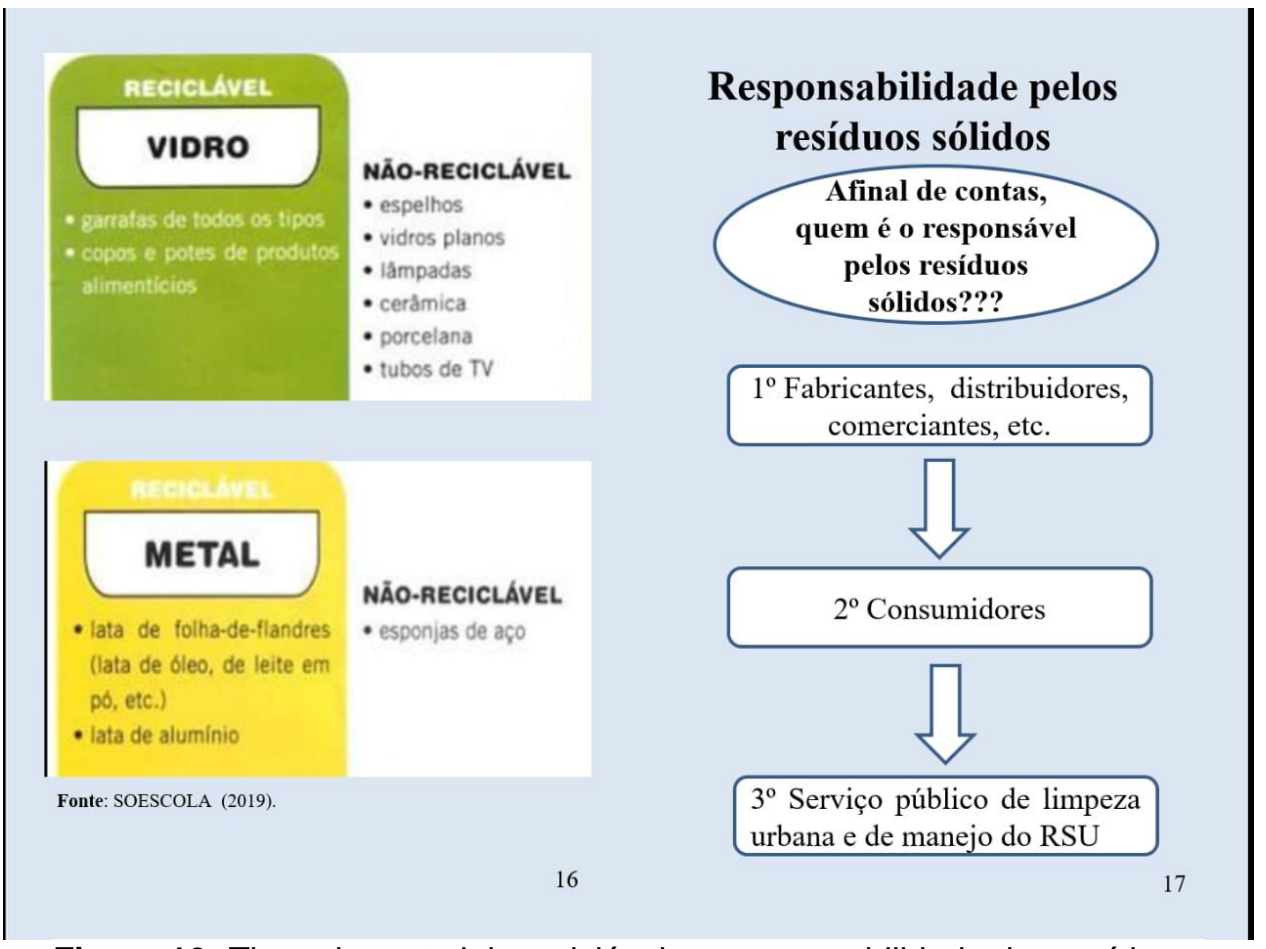

Figura 10: Tipos de materiais recicláveis e responsabilidade dos resíduos.

Fonte: Do autor (2019) 


\section{(6) Os 3R's}

Neste tópico, aborda-se sobre a estratégia da gestão de resíduos sólidos conhecida por 3R's (reduzir, reciclar e reutilizar), utilizando-se de imagens que remetem às particularidades de cada etapa. (Figura 11).

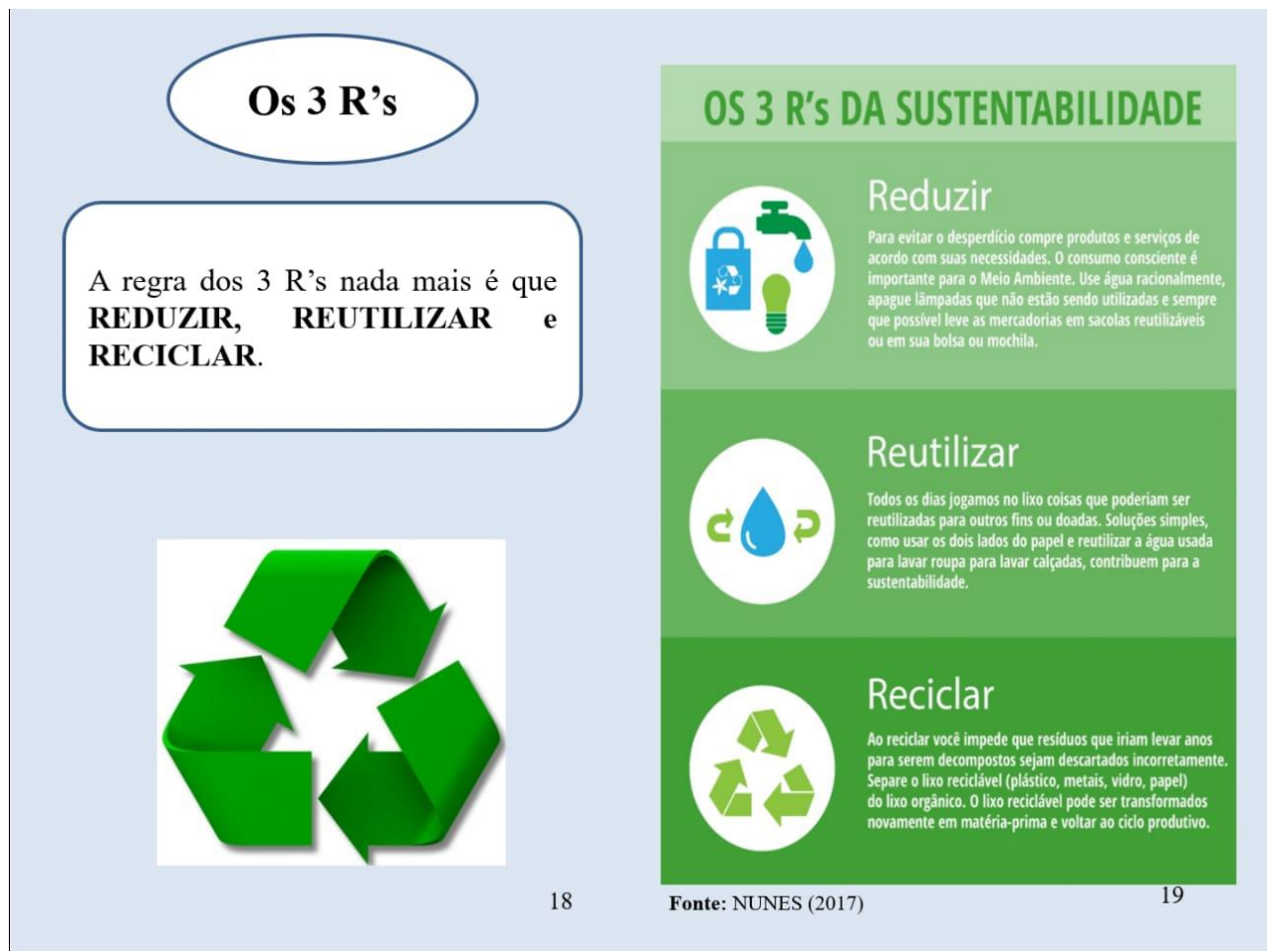

Figura 11: Descrição da estratégia 3R's.

Fonte: Do autor (2019).

\section{(7) O que é uma usina de triagem e sua eficiência}

Relata-se neste tópico sobre o conceito de usina de triagem e sua eficiência dentro da gestão de resíduos sólidos (Figura 12)

\section{(8) Usina de triagem do município}

Neste item, explanou-se sobre detalhes operacionais da usina de triagem do município e o processo de separação dos resíduos (Figura 12). Buscou-se, por meio de imagens realizadas na própria usina, destacar a situação que os resíduos chegam neste local; totalmente misturados (Figura 13 e 14). 


\section{O que é uma usina de triagem e sua eficiência}

A Central de Triagem, também conhecida como Usina de Triagem, é o local onde ocorre a separação dos resíduos sólidos. Essa separação pode ser feita manualmente, de forma automática ou semiautomática. Em primeiro lugar, para que tratamento de resíduos sólidos tenha êxito, é necessário separá-los em função das suas características físicoquímicas. Sob o mesmo ponto de vista, quanto mais separado esses resíduos, maior será o seu valor agregado. Sendo assim, a eficiência do processo esta ligada a cooperação da população.

MACHADO, 2013 20

\section{Usina de triagem do} Município de PerdizesMG

O município de Perdizes possui uma usina de separação e triagem de RSU. Os resíduos são coletados pelos caminhões de lixo e levados diretamente a usina. Após os caminhões serem descarregados na boca da esteira, eles serão separados em categorias, onde plásticos e papéis/papelões são prensados, e os demais materiais recicláveis são separados em big bags.

Figura 12: Conceito de usina de triagem e a usina de triagem do município. Fonte: Do autor (2019)

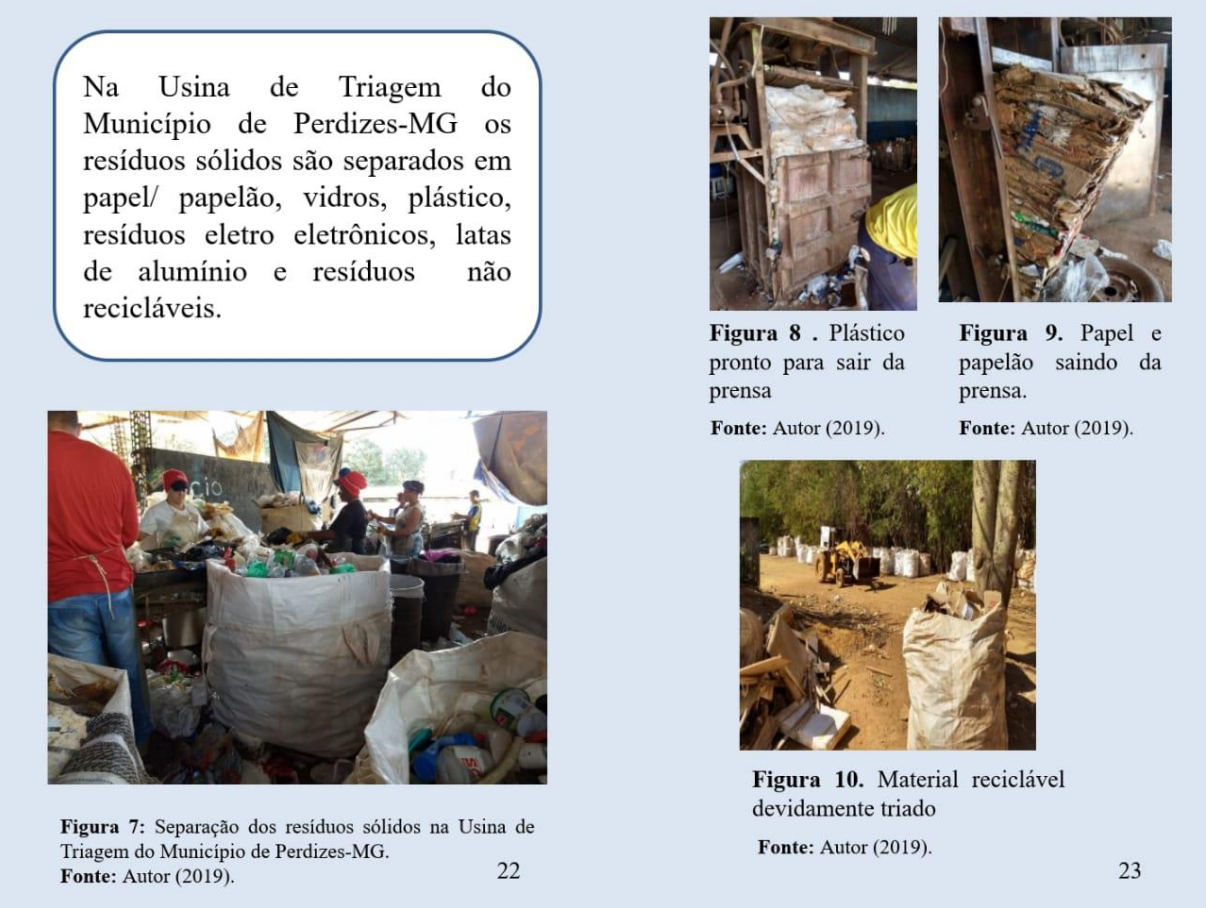

Figura 13: Usina de separação e triagem do município de Perdizes.

Fonte: Do autor (2019) 


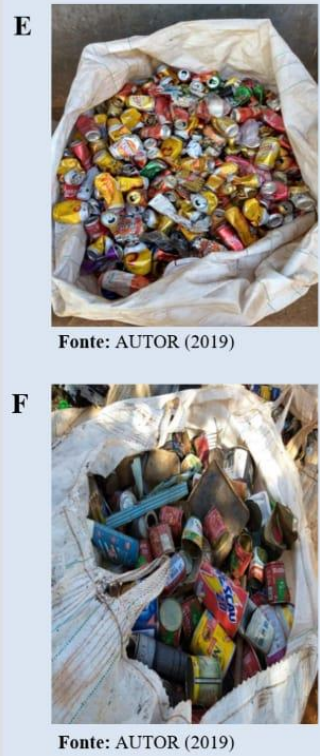

Figura 11. Latas de

alumínio

devidamente triadas

Figura 12. Latas de

metal devidamente

triadas.
G
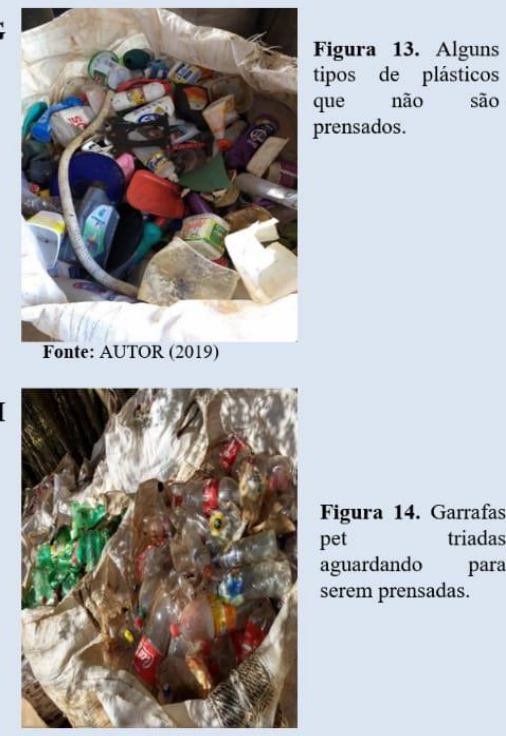

Fonte: AUTOR (2019)
Figura 14. Garrafas

pet triadas

aguardando para

serem prensadas.

Figura 14: Resíduos recicláveis devidamente separados na Usina de separação e triagem do município de Perdizes (MG). Fonte: Do autor (2019)

\section{(9) E após a separação do lixo?}

Nesta seção apresentou-se, por meio de fluxograma; o destino dos resíduos após a triagem realizada na usina de Perdizes. A imagem na cartilha visa expor o aspecto dos resíduos transportados ao aterro industrial privado localizado na cidade de Uberaba (MG) (Figura 15).

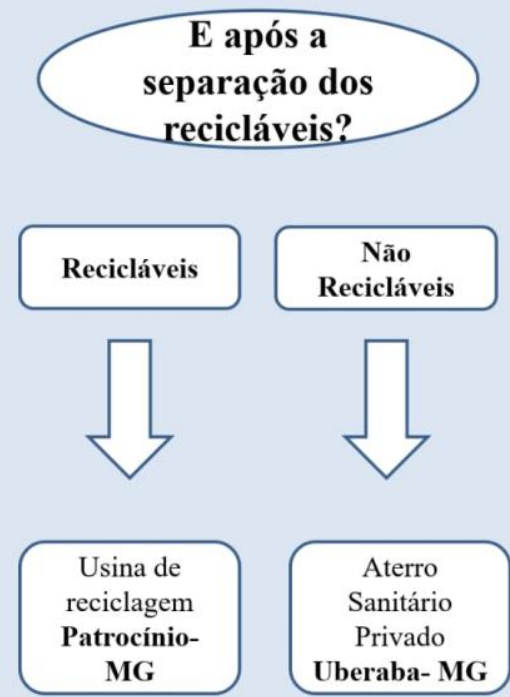

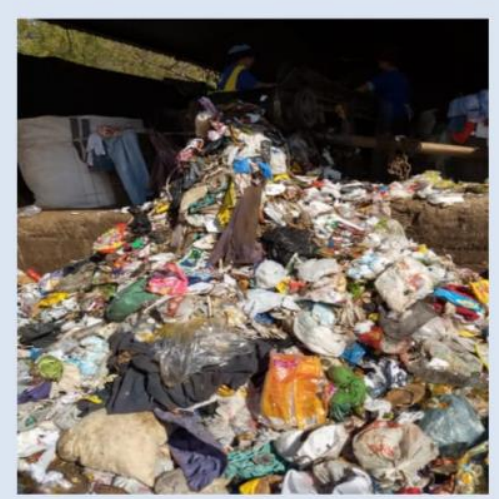

Figura 15: Material pronto para ser transportado para o aterro.

Fonte: Autor (2019)

Figura 15: Destinação dos resíduos sólidos da cidade de Perdizes-MG após separação e triagem. Fonte: Do autor (2019)

Revbea, São Paulo, V. 15, № 7: 297-313, 2020.

revista brasileira

educação ambiental 
Neste tópico, abordou-se algumas alternativas aos resíduos sólidos, como a coleta seletiva (Figura 16) e a compostagem doméstica (Figura 17), bem como o passo a passo de elaboração de composteira doméstica (Figuras 18 e 19).

Algumas alternativas aos resíduos sólidos

Coleta seletiva

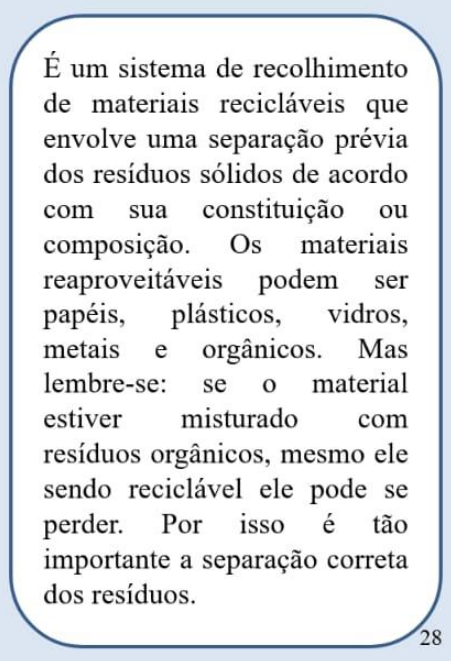

Cores das lixeiras para coleta seletiva de resíduos sólidos

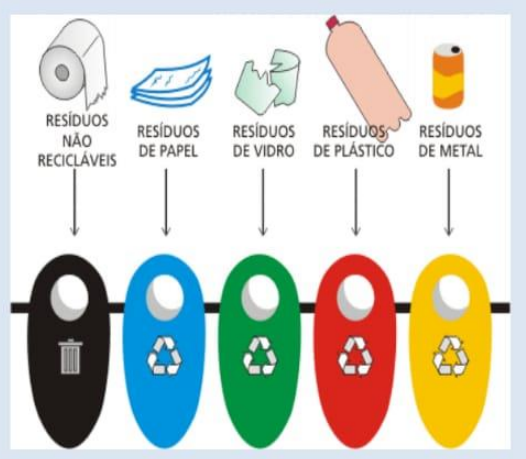

Fonte: LIMP (2016)

Figura 16: Coleta seletiva e cores das lixeiras.

Fonte: Do autor (2019)

\section{Compostagem doméstica}

Compostagem nada mais é
que a decomposição da
matéria orgânica em que o
produto final pode ser
aproveitado como adubo
orgânico. Nesse processo,
os restos de comida,
roçadas, capins, dejetos de
animais etc., podem ser
transformados em adubo
para a produção de mudas
ou na horta de casa. Para
isso, existe todo um
processo a ser cumprido,
etapa por etapa.

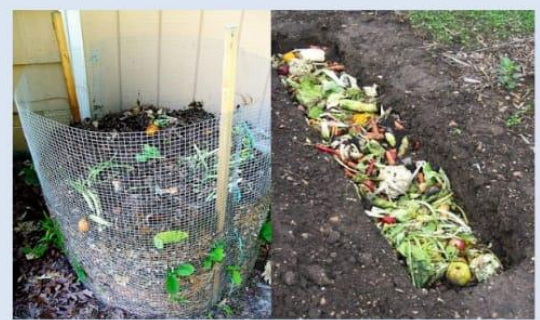

Fonte: REGHIN, 2018

29

Figura 17: Compostagem doméstica Fonte: Do autor (2019)

Revbea, São Paulo, V. 15, № 7: 297-313, 2020. 
1- Separe 3 caixas plásticas escuras (sendo uma com tampa), folhas secas, galhos pequenos e cerca de 100 minhocas (podem ser obtidas em floriculturas ou pecuárias).

2- Empilhe as caixas em três níveis. Nas duas caixas superiores será feita a compostagem e por isso elas devem ter pequenos furos, que farão a "comunicação" entre as caixas. A caixa inferior servirá apenas para a coleta do resíduo líquido orgânico.

ECOTELHADO, 2018
3- Forre o fundo da caixa superior com folhas secas, pequenos galhos ou serragem. Essa camada funciona como "dreno" para a composteira. Posteriormente, coloque a terra com minhocas e depois aplique os resíduos orgânicos.

4- Cubra os resíduos com outra camada de folhas secas para contribuir com a oxigenação.

5- Feche a caixa e aguarde. Durante os dias seguintes, faça depósitos diários de resíduos até que ela seja

Figura 18: Passo a passo de uma composteira doméstica. Fonte: Do autor (2019)

preenchida. Assim que estiver completa, basta colocar essa caixa para baixo e subir uma vazia para recomeçar o processo, não sendo preciso inserir novas minhocas.

Depois de aproximadamente três meses já é possível utilizar o adubo. $\mathrm{Na}$ última caixa, ficará acumulado o resíduo líquido orgânico que, diluído, pode ser usado para regar plantas e hortas.

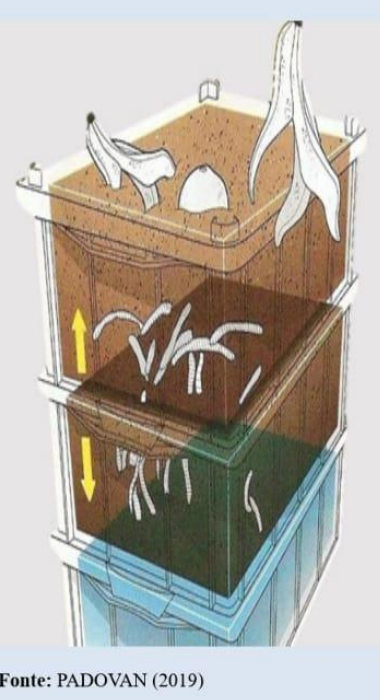

Figura 19: Passo a passo de uma composteira doméstica. Fonte: Do autor (2019) 
Neste espaço abordou-se curiosidades locais e informou-se que o município não possui local de disposição final para os resíduos sólidos gerados. Neste contexto, apresentou-se os valores gastos anualmente pela prefeitura com o transporte diário do lixo para o aterro industrial privado em Uberaba (MG). Além disso, focou-se em elementos que buscam conscientizar a população, destacando que se cada cidadão fizer sua parte os valores gastos para a destinação final dos resíduos podem diminuir, e consequentemente serem investidos em outros setores que beneficiarão toda a sociedade (Figura 20 e 21).

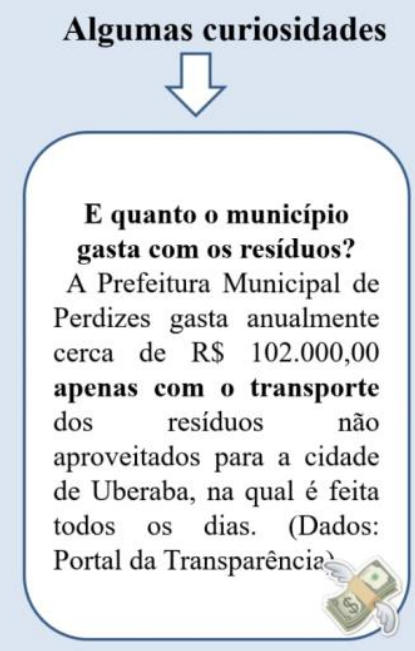

36

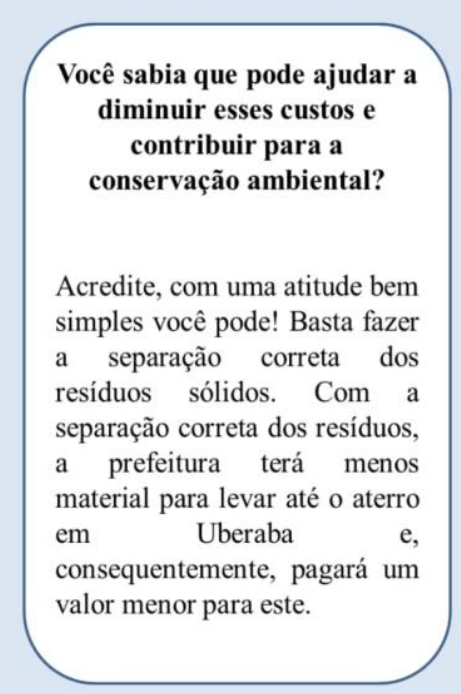

37

Figura 20: Algumas curiosidades municipais e conscientização.

Fonte: Do autor (2019)

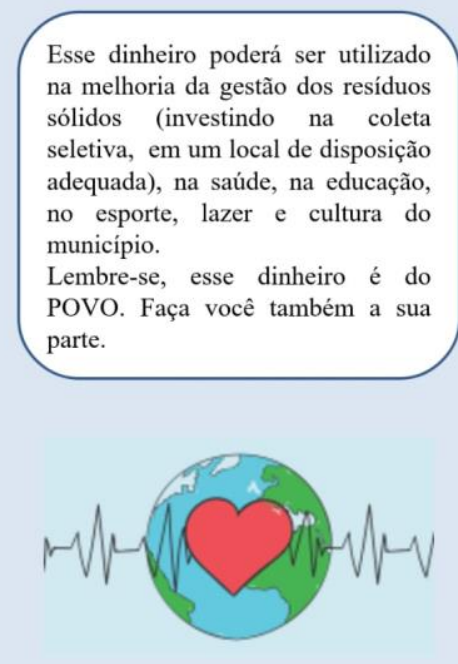

Fonte: BORGES, 2018

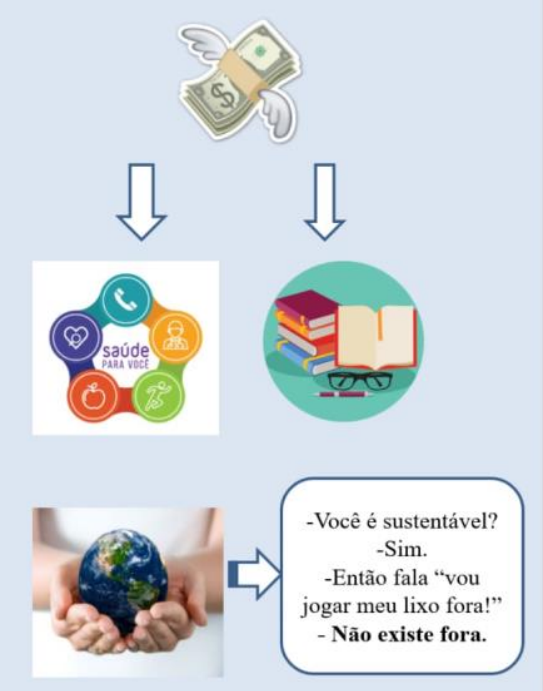

39

Figura 21: Conscientização ambiental Fonte: Do autor (2019)

Revbea, São Paulo, V. 15, № 7: 297-313, 2020. 
Por último, colocamos uma parte com as referências utilizadas para a elaboração da cartilha (Figura 22).
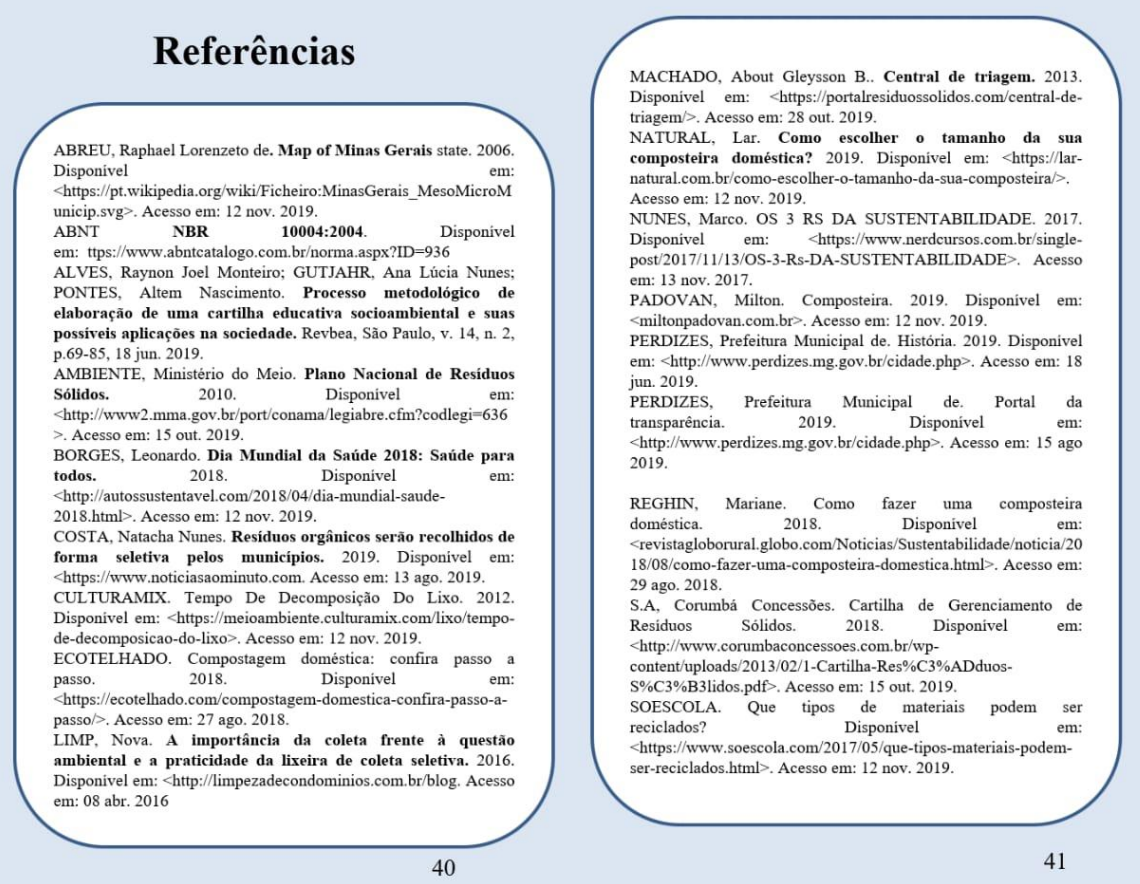

Figura 22. Referências

Fonte: Do autor (2019)

Malcher, Costa e Lopes (2013) destacam a necessidade de adaptação da linguagem no processo de aproximação do conteúdo científico a diferentes públicos. Segundo Alves, Gutjahr e Pontes (2019), cartilhas são materiais educativos, então é muito importante que tenha um recurso visual, desenhos, esquemas e ilustrações muito boas. É também essencial um layout colorido, com formas e formatações especiais. A produção de cartilhas para uma região ou município é bastante interessante, pois ressalta os problemas que determinado local possui, aliado a algumas curiosidades e por fim visa propor soluções para que a comunidade consiga solucionar ou minimizar os problemas encontrados. As cartilhas servem também para que estudantes utilizem de seu conteúdo como fonte de estudo.

Neste contexto, a cartilha produzida neste estudo foi elaborada em linguagem simples e de fácil interpretação, objetivando que a população em geral (independente da faixa etária) possa usufruir do seu conteúdo. A cartilha possui ilustrações e curiosidades, fazendo com que se torne mais interessante e visualmente mais atraente. Buscar-se-á contado com a Secretaria de Meio Ambiente e com a Prefeitura Municipal de Perdizes, para que o material seja impresso e disponibilizado aos interessados. 


\section{Conclusão}

Conclui-se que o município de Perdizes gera $15.000 \mathrm{~kg} /$ dia de resíduos sólidos. As formas de destinação são primeiramente para a usina de triagem, onde os resíduos são devidamente triados e separados. Após a triagem, os recicláveis seguem para a usina situada na cidade de Patrocínio-MG, enquanto os não recicláveis são encaminhados para o Aterro industrial privado em Uberaba-MG.

Observou-se que os resíduos sólidos urbanos chegam na usina de separação e triagem do município bastante misturados, perdendo as características de reciclagem dos mesmos. Sendo assim, concluiu-se que existe a necessidade de práticas de educação ambiental no município.

Neste contexto, como instrumento para esse processo de educação ambiental necessário; a elaboração da cartilha apresentou-se como uma ferramenta eficaz de exposição da realidade diagnosticada e de busca para o envolvimento da população, no que tange aos resíduos sólidos da cidade. Acredita-se que os temas abordados em seu conteúdo poderão contribuir para o esclarecimento da temática de resíduos sólidos à população de Perdizes, incentivando-a à um maior participação na gestão dos resíduos sólidos da cidade.

\section{Referências}

ALVES, R. J. M.; GUTJAHR, A. L. N.; PONTES, A. N. Processo metodológico de elaboração de uma cartilha educativa socioambiental e suas possíveis aplicações na sociedade. Revbea, São Paulo, v. 14, n. 2, p.69-85, 18 jun. 2019.

AMBIENTE, M. M. Plano Nacional de Resíduos Sólidos. 2010. Disponível em: <http://www2.mma.gov.br/port/conama/legiabre.cfm?codlegi=636>. Acesso em: 15 out. 2019.

BONDUKI, N. Plano Nacional De Resíduos Sólidos. 2010. Disponível em: $<$ http://www.mma.gov.br/estruturas/253/ publicacao/253 publicacao020220120 41757.pdf >. Acesso em: 19 jun. 2019.

ECOTELHADO. Compostagem doméstica: confira passo a passo. 2018. Disponível em: <https://ecotelhado.com/compostagem-domestica-confirapasso-a-passo/>. Acesso em: 27 ago. 2018.

FADINI, P. S.; FADINI, A. A. B. Lixo: desafios e compromissos. Disponível em: <http://sbqensino.foco.fae.ufmg.br/uploads/314/lixo.pdf>. Acesso em: 17 jun. 2019.

IBGE - Instituto Brasileiro de Geografia e Estatística. Cuidando do lixo. Disponível em: <www.ibge.gov.br>. Acesso em: 17 jun. 2019 
NUNESMAIA, M. F. S. Lixo: soluções alternativas. Feira de Santana: UFES, 1997. $152 \mathrm{p}$

PERDIZES, Prefeitura Municipal de. História. 2019. Disponível em: <http://www.perdizes.mg.gov.br/cidade.php>. Acesso em: 18 jun. 2019.

RIBEIRO, A. G. Plano Municipal De Saneamento Básico. 2016. Disponível em: $\quad<$ http://www.perdizes.mg.gov.br/imagens/leisord/Produto\%208\%20\%20Produto\%20Final\%20-\%20Perdizes.pdf >. Acesso em: 19 jun. 2019.

RODRIGUES, A. M. Produção e consumo do /e no espaço. São Paulo, SP: Hucitec, 1998.

ROHDEN, H. B. Conhecimentos gerais. Disponível em: $<$ www.conhecimentosgerais.com.br/ecologia/>. Acesso em: 17jun. 2019

SATO, M. Formação em Educação Ambiental - da escola à comunidade. In: Panorama da Educação Ambiental no Brasil. Brasília: MEC, março de 2000, 5-13.

SILVA, A. S. Resíduos sólidos drenados em sub-bacia hidrográfica urbana em Santa Maria - RS. Dissertação de Mestrado, Universidade Federal de Santa Maria, Santa Maria, RS, Brasil, 2010.

S.A, Corumbá Concessões. Cartilha de Gerenciamento de Resíduos Sólidos. 2018. Disponível em: <http://www.corumbaconcessoes.com.br/wpcontent/uploads/2013/02/1-Cartilha-Res\%C3\%ADduos-S\%C3\%B3lidos.pdf>.

Acesso em: 15 out. 2019

TEIXEIRA, I. M. V. Plano Nacional De Resíduos Sólidos. 2010. Disponível em:

$<$ http://www.mma.gov.br/estruturas/253/ publicacao/253 publicacao020220120 41757.pdf >. Acesso em: 19 jun. 2019.

TUCCI, C E. M.; PORTO, R.LA L.; BARROS, M. T. Drenagem urbana. Porto Alegre: ABRH, Ed. da UFRGS, 1995.

TUCCI, C. E. M. Gerenciamento da drenagem urbana. Revista Brasileira de Recursos Hídricos, v.7, n.2, p.5-27, 2002 